BULLETIN Bulletin hispanique

HispaniQuE Université Michel de Montaigne Bordeaux

119-1 | 2017

Autorité et pouvoir dans le théâtre du Siècle d'Or

\title{
Competencias entre hermanos en la tragedia calderoniana
}

Ana Suárez Miramón

\section{(2) OpenEdition}

1 Journals

Edición electrónica

URL: http://journals.openedition.org/bulletinhispanique/4933

DOI: 10.4000 /bulletinhispanique.4933

ISBN: 979-10-300-0142-6

ISSN: 1775-3821

Editor

Presses universitaires de Bordeaux

Edición impresa

Fecha de publicación: 15 junio 2017

Paginación: 285-298

ISBN: 979-10-300-0141-9

ISSN: 0007-4640

\section{Referencia electrónica}

Ana Suárez Miramón, «Competencias entre hermanos en la tragedia calderoniana », Bulletin

hispanique [En línea], 119-1 | 2017, Publicado el 15 junio 2020, consultado el 13 septiembre 2020.

URL : http://journals.openedition.org/bulletinhispanique/4933 ; DOI : https://doi.org/10.4000/

bulletinhispanique.4933 


\title{
Competencias entre hermanos en la tragedia calderoniana ${ }^{1}$
}

\author{
Ana Suárez Miramón \\ UNED
}

À une époque où conflits et rivalités marquent partout la vie, Calderón se sert de l'affrontement entre frères pour mettre en scène, de manière duelle et didactique, le faible poids de l'hérédité et de l'éducation sur le comportement humain. Sont analysés divers exemples de soif du pouvoir et d'ambition que le dramaturge résout en conformité avec les thèses chrétiennes qui coïncident avec sa défense de la liberté et de la responsabilité.

Mots-clés : Calderón, pouvoir, frères, rivalité.

En una época en que la competencia y rivalidad marcan la vida en todas las manifestaciones, Calderón utiliza la confrontación entre hermanos para escenificar de forma dual y didáctica que ni la herencia ni la educación son determinantes en el comportamiento humano. En el trabajo se analizan diferentes ejemplos que abordan el ansia de poder y la ambición y que el dramaturgo soluciona de acuerdo con las tesis cristianas más importantes de la época, coincidentes con su defensa de la libertad y la responsabilidad.

Palabras clave: Calderón, poder, hermanos, competencia.

In an era in which competition and rivalry affect life in all manifestations, Calderón used the confrontation between brothers to stage in a dual and didactic way that neither heritage nor education are determinant in human behaviour. This paper discusses different examples that address the lust for power and ambition that the playwright solves in accordance with the most important Christian doctrines in that era, coinciding with his defence of both freedom and responsibility.

Keywords: Calderón, power, brothers, competition.

1. Este artículo se inserta en el marco del proyecto de investigación FFI2014-52007-P, «Autoridad y poder en el teatro del Siglo de Oro. Estrategias, géneros, imágenes en la primera globalización», financiado por el Ministerio de Economía y Competitividad del gobierno de España. 
E término competencia, sinónimo de disputa, contienda o rivalidad define perfectamente el momento histórico en que transcurre la vida de Calderón. En el siglo XVII se producen competencias entre todo cuanto es propio del hombre: en lo artístico-literario entre escuelas, formas artísticas, de ingenio; en el mundo de la justicia entre diferentes jurisdicciones ${ }^{2}$; en el económico entre aranceles, mercados, mayorazgos y rentas; en la sociedad, entre las diferentes clases sociales; en los jardines, por conseguir las mayores audacias; en las pinacotecas, por ofrecer los mejores pinceles y en las bibliotecas por mostrar los ejemplares más originales. Incluso, como resumió Gracián, "competían Artes y ciencias» y se establecía la competencia entre todos los conocimientos que se nombran "de las tejas abajo", excluyendo la teología (Gracián 1967 : 806, b) y, por supuesto, la competencia entre Arte y Naturaleza afectaba a todas las manifestaciones, al igual que ocurría con la pintura y la literatura ${ }^{3}$. La competencia estaba relacionada íntimamente con el poder, y en una sociedad tan cambiante e inestable como la barroca, que se sentía presidida por la Fortuna, todas las posibilidades podían alcanzarse en el ejercicio de la competencia. Incluso los escritores y artistas trabajaban en su obra para acercarse al poder y obtener con él un mecenazgo para vivir ${ }^{4}$. El ejemplo de Lope, Góngora y, sobre todo, el de Quevedo resulta paradigmático ${ }^{5}$, pero todos los grandes autores tuvieron que someterse a esta situación.

En el caso de Calderón, el teatro le permitió utilizar la competencia para diferentes fines dramáticos e ideológicos. Es uno de los conceptos que más se prodiga en sus obras, con un tratamiento distinto según los géneros, pero siempre para manifestar la rivalidad de todo lo existente ${ }^{6}$, desde la propia Naturaleza en la que compiten flores y estrellas, la belleza de la mujer y la de la flor, el Sol y la Luna, la nieve y el fuego, la tierra y el aire. En la mitología, también todo es competencia; por ejemplo, entre Venus y Diana, Apolo y Júpiter; lo mismo que entre personajes bíblicos, como Demonio y Dios, árbol del Paraíso y árbol de la Cruz; Cristo y la serpiente, Gracia y Culpa, o Virgen y Culpa. También la oposición se puede encontrar entre Arte y Naturaleza; entre hermosura y discreción; soberbia y prudencia; entre ciudades; entre pretendientes al trono; entre padres e hijos; entre hermanos; entre estados de ánimo (alegría y tristeza, risa y llanto -presididos por los filósofos Demócrito y Heráclito), etc. Por ello, la tensión propia del teatro se vio favorecida en su obra

\footnotetext{
2. Incluso existían "jueces de competencias" para solucionar los conflictos de jurisdicción.

3. Recuérdese que el tema lo tuvo muy presente Calderón y lo plasmó en su Memorial en defensa de la pintura (1677).

4. Para ver múltiples ejemplos de dedicatorias de libros que buscan el amparo del poder es muy útil el trabajo de Javier Campos, 2015. Sobre los autores concretos ya hay abundante bibliografía.

5. Carlos M. Gutiérrez, 2005, ha estudiado el tema minuciosamente.

6. En La fiera, el rayo y la piedra, por ejemplo, Irífile se encarga de advertir el carácter agónico de todo lo existente (1969, pp. 1593, a-b y 1594 b) y se expresa escénicamente a partir de la oscuridad, las tormentas y terremotos.
} 
por ese sentido agónico implícito en todo lo creado y, sobre todo en el caso del hombre, por su vivencia social y su propia conciencia.

En el tema concreto de competencias entre hermanos, Calderón contaba con una gran tradición bíblica, mitológica y de innumerables ejemplos históricos, canteras que fueron utilizadas por todos los dramaturgos para sus temas. Además el teatro de Lope de Vega, Tirso de Molina y Moreto, fundamentalmente, ya habían tratado el tema y, sobre todo, los ejemplos del Derecho aportaron gran cantidad de casos que el dramaturgo utilizó para confeccionar conflictos dramáticos ${ }^{7}$. En esos conflictos se puede indagar sobre los problemas más importantes de su época, como la justicia, la economía, el poder, el amor y la ética, que, por otra parte, son los temas más importantes de su teatro y los más aptos para elaborar el juego de competencias, además de ser los más atractivos para el autor, puesto que permiten indagar en los límites de la teoría y de la praxis, de la apariencia y realidad, de lo social e individual y de la verdad y el engaño. Esos temas le permiten al dramaturgo enfrentar la norma a la conciencia, la ley a la subjetividad y, sobre todo, exponer la difícil interpretación del bien y del mal ante determinados conflictos.

Las diferentes teorías sobre el poder, la justicia, la economía y la libertad que habían surgido en la época, sobre todo entre los moralistas de la escuela de Salamanca, tienen un fiel reflejo en su obra, lo que no significa que tengan el mismo discurso, puesto que Calderón crea literatura y en su obra las teorías políticas, las interpretaciones casuistas, tacitistas y probabilististas le permitieron inventar tramas de riesgo que se acomodaban perfectamente a la compleja situación que atravesaba el país tras el progresivo declive político y social ${ }^{8}$. Como testigo y partícipe de las victorias más resonantes (Bredá y Nördlingen) y de las derrotas más demoledoras en la década de los cuarenta, a Calderón le es fácil trasponer conflictos dialécticos entre el poder y la tiranía, la paz y la guerra, o entre príncipes justos o injustos que responden a su experiencia vivida y a la propia reflexión sobre la decadencia. Por supuesto, para expresar sus teorías acude a espacios y tiempos muy alejados de su época, bajo los que fácilmente puede descubrirse la realidad de su mundo.

De entre las diferentes posibilidades de enfrentamientos en los escenarios nos parece que la competencia entre hermanos tiene excepcional importancia porque con ellos se exponen conductas antagónicas a partir de una misma naturaleza, origen y educación. Se puede establecer una gradación de intereses en su tratamiento según los géneros. En la comedia suele presentarse este tema como nudo dramático para plantear el conflicto amoroso. Los hermanos suelen

7. Fausta Antonucci ha realizado el trabajo, en prensa, titulado «Hermanos y hermanas en contienda en las comedias cómicas de Calderón (con una mirada hacia Lope)», que nos ha facilitado su autora. Es una mirada diferente al tema que abordamos nosotros, pero que ilumina la importancia del mismo en el teatro calderoniano.

8. Ver Regalado 1995, especialmente T. II, pp. 231-321. No hace falta recordar la especificidad del lenguaje literario que diferencia al dramaturgo de los teóricos de la política o del Derecho, pero sí es cierto que, tras la estética, se puede descubrir el fondo ideológico, como han demostrado estudios recientes a partir de Regalado. 
estar enamorados de la misma mujer (Mujer, llora y vencerás, Antes que todo es mi dama, La desdicha de la voz, En esta vida todo es verdad y mentira, Cuál es mayor perfección) y compiten por ella según su personalidad y cualidades. Por supuesto, los triunfadores siempre son los más discretos, sean hermanos o hermanas (No hay burlas con el amor). Por ello, y aunque en principio los hermanos sean los protagonistas del conflicto, su función va más lejos al plantear siempre una ética que, sin estar reñida con el argumento, añade un sentido de la justicia que emparienta la obra con el carácter más serio de los dramas o de los autos sacramentales. A veces sirve una breve narración o ligera alusión para añadir al conflicto amoroso primario otro más complejo y mostrar la coincidencia con obras más serias, como ocurre con La desdicha de la voz donde la protagonista, Beatriz, se queja de la falta de alimentos de su hermano, quien le debe dar el sustento. Aunque en la comedia se atienda al tema de manera superficial, el planteamiento es muy semejante al que se desarrolla en Los alimentos del hombre cuya trama constituye un serio conflicto jurídico. En Mujer, llora y vencerás ocurre algo parecido. El nacimiento de dos hermanos gemelos, opuestos entre sí (uno feliz con la guerra y el otro con los libros), sin que se sepa quién fue el primero para beneficiarse de la herencia, identifica sus diferentes "genios» a los protagonistas (Buen y Mal Genio) del auto $E l$ gran mercado del mundo aunque, como en la comedia anteriormente citada, en el conflicto no sea esencial esta trama. En El castillo de Lindabridis no hay hermanos gemelos (hecho muy frecuente en el dramaturgo) sino la ausencia de testamento, lo que lleva al enfrentamiento y a la guerra entre hermana y hermano, y las soluciones que se aplican coinciden con las utilizadas en los dramas y en los autos sacramentales, aunque la excusa sean las leyes de Babilonia que representan en Calderón el derecho natural.

En los dramas, los enfrentamientos pueden ser por una herencia (La aurora en Copacabana; Las cadenas del demonio), por el trono (Los cabellos de Absalón, Lances de amor y fortuna), por el odio de uno de los hermanos hacia el otro (Faetón, el hijo del sol; Sueños hay que verdad son) o por tener caracteres muy opuestos aunque hubieran nacido de un mismo parto (Los hijos de la fortuna, Téagenes y Cariclea). Calderón no solo se ocupa de hermanos, sino de hermanas e incluso de hermano y hermana. Por ejemplo, en Auristela y Lisidante son dos hermanas (Clariana y Auristela) quienes se enfrentan por el poder al nacer gemelas sin saber a quién le corresponde heredar.

Es en los dramas donde los conflictos generados a partir de la competencia entre hermanos por el poder resultan más complicados. Calderón en obras con protagonistas hermanos apela al código de Babilonia (como expresión de la ley natural según hemos dicho) que, durante siglos, fue un conjunto de leyes inmutable, y lo hace coincidir con la ética y la justicia que desarrollan los autos y donde el ejemplo de Cristo corrobora las tesis de los pensadores y economistas más audaces del momento, al afirmar que el heredero debía ser, siguiendo el ejemplo de Dios con Cristo, el que lo mereciera, y no el primer nacido (en cuyo caso le hubiera correspondido a Adán la herencia divina). 
Así ocurre, por ejemplo, en La exaltación de la Cruz. Los valores del «deber ser humanístico y la conciencia ética aplicada a la esfera política» (Zamora 1989: 35), los trata de encontrar el dramaturgo, tras una compleja tensión en escena, en todos los géneros y temas que aborda.

La presencia y enfrentamiento de dos hermanos puede surgir en una obra religiosa, como es el caso de Las cadenas del demonio. Hay una doble acción en la que participan los hijos del rey de Persia, Cósdroas. En un determinado momento, el rey decide dejar el trono a uno de sus hijos para ir a la guerra y nombra al hijo que aparentemente se lo merece más, según las costumbres orientales («Sabéis que es costumbre usada/ de Persia, que entre sus hijos/ (sin que mayor edad valga)/ puedan elegir los reyes/ sucesor: ley soberana/ que mira a que no porque/ primero uno que otro nazca, /cińa la sacra diadema,/ sino porque sea su fama/ más digna de ella») (Calderón de la Barca 1969: 949, b - 950, a). Sin embargo, su decisión de dejar a Menardes, el más impulsivo e instintivo de los dos, y quien nunca había demostrado valor ni honor auténtico (pues presentaba como victorias propias las conseguidas por su hermano Siroes), no deja indiferente a este, quien se considera ofendido, pues su comportamiento siempre había sido virtuoso y leal. No acepta la marginación a que le someten y jura vengarse. Tras aliarse con Heraclio, enemigo de su padre, hace prisionero al rey y a su hermano y consigue ser nombrado sucesor legítimo. Su conducta para conseguir el trono no resulta nada ejemplar ni siquiera para él mismo, quien confiesa haber «enmendado" aunque «con alguna indignación» su fortuna. Con esa extraña actitud vengativa de quien antes había sido reflexivo y tranquilo, el dramaturgo insiste en la necesidad de nombrar rey a quien posea más méritos y, aunque por momentos en esta obra parece que el fin justifica los medios, principio maquiavélico y extraño en la dramaturgia calderoniana", enseguida vuelve de la guerra el padre y ocupa el trono. Lo que podría haber sido un triunfo de la injusticia queda solucionado por la victoria de Cósdroas, que hace innecesaria su sucesión.

Sin embargo, en la obra se puede ver muy bien la proximidad que existía entre competencia y venganza, tal como afirman muchos protagonistas de comedias, dramas y autos. En este caso la venganza se utiliza para restablecer una justicia que la fortuna había negado, pero esa aparente justicia no se hace definitiva gracias a la ética y el pensamiento cristiano. Por ello, todo queda en una lección doble, la que recibe el hijo por su comportamiento, lo que viene a demostrar al final la sabia elección primera del padre, y la necesaria inhabilitación de un rey cuando utiliza procedimientos desleales y traidores aunque sean para restablecer una causa justa.

En Los hijos de la Fortuna, Teágenes y Cariclea, se plantea también otro caso de injusticia similar al anterior, pero aquí la competencia surge entre hermanos nacidos de un mismo parto aunque con inclinaciones distintas. En la obra, Tíamis se siente desposeído del poder que considera merecer. Su padre se lo ha otorgado a su hermano Petosiris y él busca vengarse para reparar su afrenta

9. Aunque eficaz para plantear la tensión dramática y el tema moral. 
(y lo hace de su padre, patria y hermano). Para ello se hace bandolero y asalta a los habitantes de la ciudad donde gobierna Petosiris. Un accidente le lleva a naufragar y es socorrido por la reina de Etiopía, Persina, a quien cuenta su historia de rencor, al tiempo que le propone un plan para secuestrar al rey ${ }^{10} \mathrm{y}$ consumar su venganza. Sin embargo, por haber salvado de la muerte a la que iba a ser esposa de su hermano, obtiene el perdón y por su lealtad, el hermano sigue al frente del reino.

Como en la obra anterior, en esta la venganza y soberbia no triunfan porque el comportamiento de Tíamis pone en evidencia su incompatibilidad con las cualidades que debe tener un buen gobernante. A lo largo de la obra se van mostrando evidencias que le descalifican como posible rey y, por tanto, aunque la venganza hubiera podido ser un medio para obtener un fin justo, no resulta viable aplicar esa clase de justicia en favor de algo tan profundamente injusto como poner al frente de un pueblo a un poderoso capaz de arrasar, prender fuego a una ciudad, traicionar y matar para conseguir un propósito determinado. De nuevo, y con un ejemplo práctico, la teoría maquiavélica se ve superada por las tesis cristianas ya puntualizadas por Erasmo (La educación de un príncipe cristiano), utilizadas por Tomas Moro (Utopia), defendidas por Quevedo (Política de Dios y gobierno de Cristo) y ampliadas en ejemplos concretos en Saavedra Fajardo, basadas todas en que el gobierno debe estar representado por los mejores y por quienes tengan virtudes cristianas.

Otro enfrentamiento entre hermanos, más bien entre dos adolescentes que han crecido como hermanos siendo uno hijo del rey Focas, al que consideraba muerto, y el otro, heredero de Mauricio, rey de Constantinopla, a quien mató el tirano Focas y usurpó el trono, se desarrolla en el drama En esta vida todo es verdad y todo mentira. Focas no puede saber quién es Leónido y quién Heraclio $y$, aunque para asegurar su destino debe acabar con el hijo de su enemigo, su duda alcanza proporciones trágicas al no saber si será su propio hijo la víctima. Aunque es Focas el verdadero protagonista, la pareja representa la antítesis entre la arrogancia, el orgullo y carácter instintivo de Leónido y la valentía, prudencia y reflexión de Heraclio, pese a que los dos, como Segismundo, se han criado en una cueva al cuidado del sabio Astolfo, a quien llaman padre. Este carácter salvaje y virgen de los jóvenes en el terreno político es utilizado por el dramaturgo para presentar un conflicto que nace solamente cuando se sabe que uno de ellos es heredero del trono. Al ansia por ocupar el poder se añade la duda de no saber quién de ellos es el verdadero hijo del tirano y, por tanto, rechazado con toda probabilidad.

Cuando ambos son descubiertos en la cueva, Astolfo da una prueba a Focas de que uno de ellos es el hijo suyo, a quien creía muerto, pero no le dice quién

10. En las palabras de Idaspes a Persina puede verse un razonamiento muy parecido al comportamiento de Segismundo con el soldado rebelde (en La vida es sueño): «ahora nos valgamos déste/ que después nos guardaremos»: «Político dogma es éste/ de que cuanto la traición/ agrada, el traidor ofende» (Pedro Calderón de la Barca, Los hijos de la fortuna, Teágenes y Cariclea, OC. I, Madrid, Aguilar, 1969, p. 1165, a). 
de los dos es. Para saberlo lleva a los dos a palacio y realiza, como Basilio con Segismundo, diversas pruebas para conocer el comportamiento de cada uno. Al principio, el experimento no funciona, porque, incluso aislado uno del otro, ambos responden igual y positivamente a cuanto se les pregunta, pero cuando aparece Astolfo y les explica la realidad todo se complica. Entonces comienzan a diferenciarse en su comportamiento, hasta mostrar Leónido una total agresividad y una ambición desmedida por reinar ( $Y$ Y pues en mí no hay más/ ni más razón ni más juicio/ que desear reinar»)-(Calderón de la Barca 1969: 1211, a), mientras que Heraclio parece conformarse con llegar a saber si Focas es su verdadero padre. Por ello, cuando ve que su hermano trata de matar a Focas, se interpone, pero el tirano cree que el traidor ha sido Heraclio. Al fin se llega a conocer que es Leónido, el hijo de Focas, a quien nombran sucesor.

Para evitar conflictos, y en recuerdo de los ańos que vivieron juntos en la cueva, padre e hijo deciden perdonar la vida de Heraclio, pero le expulsan del reino. Hasta aquí todo parece un ejemplo de herencia natural (de Focas a su hijo), y sin embargo, puesto que Focas había usurpado de malas formas el trono, la obra da un giro en este aparente desenlace y vuelve a plantear un nuevo espacio de reflexión política. Un nuevo y simbólico naufragio (como en el ejemplo anterior) logra cambiar los acontecimientos. Heraclio es salvado por Federico y, de vuelta a la corte, una vez que Focas ha muerto, se logra saber definitivamente que Heraclio es el verdadero hijo de Mauricio y a quien corresponde legítimamente el reino de su padre. De ese modo, los dos hermanos, cada uno con un carácter distinto, producto de su herencia respectiva aunque de igual educación, consiguen acceder al poder y, hemos de suponer que por las cualidades innatas de ambos, el hijo del traidor manifiesta alguna generosidad al perdonar la vida a quien creció a su lado como hermano, aunque le considerase posible enemigo. Esta virtud tiene su recompensa cuando se demuestra que le corresponde a Heraclio el trono de su padre y es capaz de reinar con magnanimidad ${ }^{11}$. Además de la sucesión de acontecimientos en las pruebas, lo interesante es el proceso dramático y los cambios progresivos, desde la inocente mirada de ambos, a los rencores y enfrentamientos posteriores ante la posibilidad de obtener el trono.

Sin embargo la competencia por reinar puede interpretarse en esta obra como la imposibilidad de saber a ciencia cierta a quién puede corresponder el trono y si es más justo que sea para un hijo legítimo (aunque sea descendiente de un traidor) o para aquel que ha mostrado un comportamiento más perfecto y lo merece aunque no pueda heredar por diversos factores (aquí por haberle arrebatado el trono un tirano). Los dos desenlaces están contemplados y apuntalados desde el principio por la idéntica educación de los jóvenes, lo cual explicaría que la rivalidad entre ellos no llegue hasta las últimas consecuencias.

La obra pone de relieve los laberínticos recovecos del poder, las dificultades para conocer la verdadera personalidad de los posibles sucesores y la fragilidad y brevedad del mando que, como un sueño, se puede ganar y perder en un

11. Para la magnanimidad y su valor en el teatro de Calderón, ver Rull, 2007. 
tiempo muy breve. La obsesión de Focas por matar a uno de ellos para asegurar la tranquilidad del imperio se desvanece cuando se entera de que puede matar a su hijo. Esa debilidad, en términos maquiavélicos, derivará en el conflicto entre los hermanos y la siguiente debilidad, la de dejar libre a Heraclio, traerá consigo la pérdida del trono. La tesis de Maquiavelo de que no vivirá seguro ningún soberano si no termina con el tirano que ha arrebatado el poder, se justifica en la obra, pero también y, desde otra perspectiva, puede descubrirse una enseñanza moral que, desde luego, parece reñida con la política y se ajusta más al pensamiento político cristiano. Los hermanos se tienen un gran afecto mutuo hasta que son conscientes de lo que representa el poder. Entonces la rivalidad los enfrenta pero nunca llegan a olvidar del todo el afecto del uno por el otro. Esa debilidad le hace perder el poder a uno y mostrar que solo triunfa quien acaba con sus enemigos. Sin embargo, no se lleva hasta el final la teoría de Maquiavelo porque Heraclio no es capaz de matar a su hermano y solo le expulsa de su reino. Esa magnanimidad trae consigo que le arrebaten el trono pero también, por esa acción, al final se muestra victorioso el verdadero hijo de Mauricio, quien legalmente había sido el rey y a cuyo hijo le correspondía el trono. En esta ocasión la tesis y experimentación maquiavélica se ve superada por las virtudes cristianas del nuevo rey, quien también perdona a su rival. Se podría afirmar que la solución del conflicto se ajusta a las palabras de Quevedo «la diferencia del gobierno de Cristo al gobierno del hombre» (Quevedo 1966: 583, a) y a la justificación que el autor de La política de Dios hace en el primer capítulo:

Advirtiendo cuán mal se gobernaban los hombres por sí después que fueron posesión del pecado, y que unos de otros no podían aprender sino doctrina defectuosa, y mal entendida, y peor acreditada por la vanidad de los deseos [...] determinó de bajar en una de las personas o gobernar y redimir al mundo, y a enseńar [...] la política de la verdad y de la vida. Bajó en la persona del Hijo, que es el verbo el entendimiento, y fue enviado por legislador al mundo Jesucristo, hijo de Dios, y Dios verdadero. Después le siguió el Espíritu Santo, que es el amor de la voluntad. Descienda el discurso a nosotros.

El entendimiento bien informado guía a la voluntad, si le sigue. La voluntad, ciega e imperiosa, arrastra al entendimiento cuando sin razón le precede. Es la razón que el entendimiento es la vista de la voluntad y, si no preceden sus ajustados decretos en toda obra, a tiento y a escuras caminan las potencias del alma. ${ }^{12}$

La estatua de Prometeo puede servir de ejemplo representativo de la utilización de un mito por parte del dramaturgo para adaptarlo a un fin superior, como es mostrar la naturaleza agónica del individuo a partir del desdoblamiento de un personaje, metáfora para representar a los humanos. En esta obra, además de insistir en la importancia de la libertad y el deseo de saber por parte de Prometeo, se presenta un doble conflicto entre hermanos y hermanas. La oposición entre hermanos deriva de su diferencia entre razón (Prometeo) y pasión (Epimeteo), y en el caso de las hermanas, hijas de Júpiter y Letona, de 
su contraria personalidad (Palas, inclinada a la guerra, y Minerva a las letras). Con este doble juego, Calderón manifiesta, por una parte, la necesidad de tener educación y saber muchas materias para elaborar leyes, y, por tanto, para ser buen gobernante, $y$, por otra, los errores a que conduce la guerra si se hace de forma irreflexiva por quien no tiene conocimientos y dirige un pueblo. Aunque no es el tema esencial de la obra, sí se pueden espigar en ella interesantes comentarios acerca del poder y la justicia por parte de los enfrentados hermanos a pesar de haber nacido de un mismo parto ("Opuestos crecimos, no/ en la voluntad que anuda/ nuestros corazones, pero/ en la inclinación que muda/ los genios») (Calderón de la Barca: 1969: 2068, a). Paralelamente, las dos hermanas muestran la misma divergencia a pesar de su idéntico nacimiento («crecimos las dos opuestas/ en los divididos genios/ de nuestras dos influencias:/ blanda ella lo diga,/ dígalo soberbia/ yo dictando lides, / dictando ella ciencias" ${ }^{13}$ ) y a Minerva le corresponde declarar, a modo de eco, la enseńanza de Prometeo, que «entre ingenio y valor,/ más que la fuerza del brazo/ vale la de la razón»»'). El conflicto entre hermanas surge a partir de la tutela que ambas tienen sobre sus hermanos, las confusiones que crean y el engaño al que es abocado Prometeo con sus errores consiguientes.

Prometeo representa no solo el ansia de saber para ser «más humano», sino para imponer en el mundo bárbaro e ignorante de sus compatriotas otros «preceptos» de "político gobierno» que superen las leyes naturales con las que está feliz el pueblo, según advierte Epimeteo: «contentos con nuestras leyes (que son las dos que ejecuta/ el pueblo cuando castiga/ al que mata y al que hurta) $»^{15}$. Del enfrentamiento entre hermanos y hermanas se desprende la necesidad del estudio y del conocimiento para poder gobernar una sociedad. En esta tesis coincide el dramaturgo con lo propuesto en la Empresa II de Saavedra, que recoge la idea platónica contenida en Las Leyes: «la enseñanza mejora a los buenos, y hace buenos a los malos», y donde apuesta por el valor de la educación para conseguir la felicidad del pueblo «porque son instrumentos de la felicidad política y de la salud pública ${ }^{16}$. Puede observarse también la identidad de materias que ha de conocer un príncipe, según Saavedra, y las que Prometeo afirma haber cursado durante su estancia en Asia, considerada cuna del saber, pues no había posibilidad de hacerlo en su tierra ignorante.

Otro enfrentamiento entre hermanos por el trono puede verse en la tragedia bíblica Los cabellos de Absalón ${ }^{17}$. Adonías y Absalón, hijos del rey David, compiten primero por el trono reservado a su otro hermano, Amón. En la obra hay una perfecta gradación de lo que es una ambición sin límites por parte de Absalón. Primero, cuando se entera de la tristeza que aqueja al heredero,

13. Ibid., p. 2074, a.

14. Ibid., p. 2095 , b.

15. Ibid., p. 2070, b.

16. Diego Saavedra Fajardo, Idea de un príncipe politico cristiano representada en cien empresas, OC, Madrid, Aguilar, 1940, p. 175, a.

17. Recuérdese que el acto segundo de esta obra está tomado del acto segundo de La venganza de Tamar, de Tirso de Molina. 
muestra la ausencia de todo sentimiento que no sea su codicia de reinar ( $S$ Sí, que es heredero heroico/ de David, y si él se muere,/ quedo yo más cerca al solio;/ que a quien aspira a reinar/ cada hermano es un estorbo») (Calderón de la Barca 1969: 832, a).

Los episodios siguientes corroboran una obstinada ambición que cada vez se va haciendo más honda y enfermiza: primero, al interpretar unas palabras de la pitonisa Teuca sobre la belleza de sus cabellos en beneficio suyo («bien infiero/ que esta adoración común/ resulte en que todo el pueblo/ para Rey suyo me aclame,/ cuando se divina el reino/ en los hijos de David») ${ }^{18}$; después, al enfrentarse con su hermano Adonías, por creerse merecedor del reino; más tarde, al conocer la violación de Tamar y la debilidad de su padre para castigar a Amón, que le impulsa a acabar con su vida («con su muerte cumplirél su justicia y mi ambición.») ${ }^{19}$ y, finalmente, cuando encuentra la corona real, decidiendo matar a sus posibles rivales, Amón y su propio padre ("¿Quién hay en Jerusalén/ que lo estorbe?/ Amón. Matalle./ Mi padre querrá vengalle./ Matar a mi padre») $)^{20}$.

El dramaturgo reitera constantemente la pasión de Absalón por la corona y pone al descubierto sus sentimientos en los preparativos del asesinato («Sobre el trono me he de ver/ de mi padre coronado./ Muera en el convite Amón,/ quede vengada Tamar,/ dé la corona lugar/ a que la herede Absalón») ${ }^{21}$, en su realización, y en su nuevo odio, ahora hacia Salomón, el otro hermano al que cree dará la corona su padre. Sin tener en cuenta el perdón de su padre por el crimen de su hijo, decide al fin hacer la guerra a sus hermanos para coronarse rey, y reta a muerte incluso a su propio padre («que no se esconda de mí,/ que en la campaña le espero/ por afrentar con su muerte/ la corona y el imperio./ Decir que traiga a sus hijos/ consigo, porque en muriendo/ él a mis manos acabe/ de una vez con todos ellos») ${ }^{22}$.

En la enajenación del protagonista se va mostrando la ausencia de todo sentimiento humano, centrado únicamente en quitar obstáculos de su camino. Por ello, la obra termina con el equilibrio que para el bien público representa el tiranicidio, en este caso de un príncipe, tal como afirma Joab: («Menos una vida importa,/ aun de un príncipe heredero,/ que la común inquietud/ de lo restante del reino»). Su actuación en nombre de la razón de estado («La justa razón de Estado/ no se reduce a preceptos/ de amor: yo le he de matar») ${ }^{23}$ desvela la necesidad de imponer la ley por encima de cualquier sentido de perdón a quien no lo merece. Aunque la obra no se ha considerado de intriga política en sus tres $\operatorname{actos}^{24}$, sin embargo, analizando el proceso de Absalón, sí

18. Ibid., p. 838, a.

19. Ibid., p. 844, a.

20. Ibid., p. 844, b.

21. Ibid., p. 848, a.

22. Ibid., p. 862, b.

23. Ibid., p. 863, a-b.

24. Ver el estudio de E. Rodríguez Cuadros, 1989, especialmente el apartado «La dura razón de estado", pp. 73-78. 
se puede afirmar que desde el comienzo hay una evidente competencia entre hermanos, y el protagonista, por diversas causas, va enfrentándose a uno tras otro con la intención de terminar contra todo lo que pueda hacerle perder el trono.

La explícita alusión final a la razón de estado, pronunciada por Joab, actualiza el pensamiento de Maquiavelo para quien la obligación de conservar un reino había de enfrentarse, si fuera necesario, "contra la caridad, contra la humanidad y contra la religión» (Maquiavelo 2013: 127) y Joab cumple este principio al no hacer caso a los ruegos del rey (que pedía conservasen la vida de su hijo) ni tener lástima por su muerte. Por otra parte, se pone en práctica también la justificación de Saavedra Fajardo sobre el mismo tema que, a diferencia de Maquiavelo, insistía en la necesidad de mirar por el pueblo, tesis que se avala también en esta obra. Aunque tienen cabida las dos ópticas, no hay contradicción, pues Absalón se parece más a un monstruo que hay que extirpar de la sociedad (como el Nembrot de La torre de Babilonia) y Joab mira sobre todo por su pueblo ${ }^{25}$. Asimismo, en el comportamiento de David, se muestra el otro riesgo de los gobernantes, el de ser demasiado misericordiosos, cuya consecuencia obliga, en este ejemplo, al tiranicidio y a desobedecer al propio rey en favor de su pueblo. A este respecto, la enseñanza de Saavedra Fajardo en la Empresa XXII parece una lección para el personaje bíblico cuando advierte de los peligros de una extremada clemencia por parte de los reyes:

Ninguna cosa es más dañosa que un príncipe demasiadamente misericordioso. En el Imperio de Nerva se decía que era peor vivir sujetos a un Príncipe que todo lo permitía que a quien nada; porque no es menos cruel el que perdona a todos que el que a ninguno, ni menos dańosa al pueblo la clemencia desordenada que la crueldad y a veces se peca más con la absolución que con el delito. Es la malicia muy atrevida cuando se promete el perdón. ${ }^{26}$

Otro caso diferente se plantea en Las cadenas del demonio, al hilo de un tema teológico. La complicación aumenta por la presencia de dos hermanos y su hermana, Irene, hija del rey Polemón, quien, como en el caso de Segismundo en La vida es sueño, había condenado al encierro por el vaticinio de un horóscopo. A ella le correspondía ser heredera de Armenia («imperio/ es del grande Polemón,/ de cuya corona y cetro/ hija heredera nací,/ si hubiese querido el Cielo/ que se midiesen iguales/ fortuna y merecimiento") (Calderón de la Barca 1969: 646, b). Sin embargo, la posible elección de uno de los hermanos gemelos, Licanoro y Ceusis, sobrinos de Polemón, para ocupar el trono, se ve alterada por la libertad de Irene, conseguida gracias al poder del Demonio. Si en principio solo los dos hermanos iban a ser competidores, la liberación de Irene por San Bartolomé enreda el conflicto. Los hermanos, «encontrados» $\mathrm{y}$ «opuestos» en acciones y costumbres, son sometidos a una

25. El tema, en su vertiente cristiana, lo desarrolló Calderón en el auto A Dios por razón de estado. Ver el estudio de J. E. Duarte, 2014, pp. 9-47.

26. Diego Saavedra Fajardo, op. cit., p. 275, b. 
prueba, que en este caso se centra en la valoración de la paz frente a la guerra, equivalente a la creencia o no en el cristianismo. Ceusis, partidario de la guerra y con todos sus defectos («ambicioso, soberbio,/ cruel, homicida, tirano,/ lascivo, injusto y violento» ${ }^{27}$ ), desafía a Licanoro, amante de la paz, estudioso, "abatido,/ postrado, humilde y sujeto» ${ }^{28}$. Su triunfo no es en una batalla bélica solo, sino en la creencia en el verdadero valor del Cristianismo, al que ya Irene se había convertido. El enfrentamiento del pueblo en dos bandos, el presidido por la idolatría y mandado por Ceusis, y por el cristianismo, abrazado por su hermano e Irene, que representan otra visión de esa competencia, pero igualmente simbólica para los fines del dramaturgo de defender el valor ético y cristiano del gobernante.

En esta obra, como las anteriores, se respaldan totalmente las tesis de Erasmo, La educación de un príncipe cristiano, dedicada a Carlos V, y de extraordinario éxito en España desde su publicación en 1516. Aunque los ecos de Erasmo estuviesen difuminados en la época de Calderón, su propuesta dedicada a Carlos V, seguía viva porque los principios cristianos defendidos por él tenían plena vigencia, aunque se hubiera olvidado su autor. En la obra se puede descubrir la importancia del cristianismo para un príncipe perfecto, no solo por las virtudes propias, sino porque ese pensamiento llevará implícita la paz. Si Erasmo consideraba incompatible con un príncipe cristiano todos los vicios que Ceusis reúne, Calderón, con independencia de que hubiera seguido o no al pensador, explicita las razones teológicas en las que debe basarse el buen príncipe ${ }^{29}$ y, como él, consideraba había de ser el retrato vivo de Dios, en oposición al mal príncipe, retrato del Demonio. Las mismas razones que se encuentran en Erasmo aparecen perfectamente expresadas en esta obra de Calderón. Como analizó Ariza ${ }^{30}$, también las coincidencias de Erasmo con Quevedo, en su concepción del príncipe perfecto, evidencian el sentido teológico del gobernante, idea también presente en Saavedra Fajardo y que Calderón expone perfectamente en esta obra.

Con estos ejemplos, que podrían extenderse a otras obras, se puede extraer una consecuencia dramática en la utilización de los hermanos: la posibilidad de exponer diferentes planos sincrónicos de comportamiento humano aun con la misma naturaleza y educación. El hecho de que sean idénticos en muchos casos, o hijos de unos mismos padres (o criados y enseñados por un ayo común), le permite al autor experimentar con el problema de la conciencia individual, que queda así al descubierto y sin otra justificación achacable a elementos sociales, culturales o familiares. El individuo aparece aislado frente a sus pasiones (o virtudes) y se hace totalmente responsable de sus actos. Además, al igual que Erasmo buscaba ante todo educar al príncipe a partir de la experiencia y del pragmatismo, Calderón expone en el escenario situaciones

\footnotetext{
27. Ibid., p. 648, a.

28. Ibid., p. 648, a.

29. Erasmo, 1996.

30. Ver Ariza, 1996.
} 
posibles donde la justicia, el perdón, la venganza, el deseo y la ambición se expresan dialécticamente gracias a la presencia de hermanos cuyas voluntades pueden llevar a ejercer su misión desde posturas antagónicas. El resultado es que cada comportamiento constituye una lección de responsabilidad personal y de ejercicio de la libertad, con independencia de imposiciones o educación.

\section{Bibliografía}

Antonucci Fausta, «Hermanos y hermanas en contienda en las comedias cómicas de Calderón (con una mirada hacia Lope)» (en prensa).

Alcalá-Zamora y Queipo de Llano J., La reflexión politica en el itinerario calderoniano, Madrid, Real Academia de la Historia, 1989.

Ariza Canales M., «Metáforas del poder: iconografía de la política cristiana en Erasmo y Quevedo», Literatura emblemática hispánica. Actas del I simposio internacional, ed. S. López Poza, Coruña, 1996, pp. 293-302.

Calderón de la Barca P., A Dios por razón de estado, ed. crítica de J.E. Duarte, PamplonaKassel, Universidad de Navarra - Edition Reichenberger, 2014.

— En esta vida todo es verdad y todo mentira, OC. I, Madrid, Aguilar, 1969, pp. 1109-1151.

- La estatua de Prometeo, OC. I, Madrid, Aguilar, 1969, pp. 2067-2097.

- La fiera, el rayo y la piedra, OC. I, Madrid, Aguilar, 1969, pp. 1593-1638.

- La exaltación de la cruz, OC. I, Madrid, Aguilar, 1969, pp. 985-1018.

— Las cadenas del Demonio, OC. I, Madrid, Aguilar, 1969, pp. 645-673.

- Los cabellos de Absalón, OC. I, Madrid, Aguilar, 1969, pp. 829-864.

- Los hijos de la fortuna, Teágenes y Cariclea, OC. I, Madrid, Aguilar, 1969, pp. 12251268.

Campos y Fernández de Sevilla J., ¿Imagen del poder? (Lisonja y mecenazgo en el arte), San Lorenzo de El Escorial, Instituto Escurialense de Investigaciones Históricas y artísticas, Estudios Superiores de El Escorial, 2015.

Gracián B., El Criticón, Obras Completas, ed. Arturo del Hoyo, Madrid, Aguilar, 1967, $3^{\text {a }}$, pp. 517-1013.

Gutiérrez C. Ma., La espada, el rayo y la pluma. Quevedo y los campos literario y de poder, West Lafayette, Pardue University Press, 2005.

Maquiavelo, El principe, Barcelona, Ariel, 2013.

Quevedo F., Politica de Dios y gobierno de Cristo, OC., I, Prosa, Madrid, Aguilar, 1966, pp. 526-701.

Regalado A., Calderón. Los origenes de la modernidad en la España del Siglo de Oro, 2 vols, Barcelona, Destino, 1995.

Rodríguez Cuadros E., Introducción a Los cabellos de Absalón, Madrid, Espasa Calpe, «Clásicos Castellanos», 1989.

Rotterdam Erasmo de, Educación del príncipe cristiano, Madrid, Tecnos, 1996.

Rull E., «Vencedores y vencidos en el teatro de Calderón», Guerra y paz en la comedia española, Actas de las XXIX Jornadas de Teatro Clásico de Almagro (Almagro, 4-6 de julio de 2006), ed. de Felipe B. Pedraza Jiménez, Rafael González Cañal y Elena E. Marcello, Cuenca, UCLM, 2007, pp. 157-176.

Saavedra Fajardo D., Idea de un príncipe politico cristiano representada en cien empresas, OC, Madrid, Aguilar, 1940, pp. 158-691. 
